\title{
Vapor permeation studies of membranes made from molecular squares
}

\author{
Kenneth F. Czaplewski ${ }^{\text {a }}$, Jialiang Li ${ }^{\text {b }}$, Joseph T. Hupp ${ }^{\text {b }}$, Randall Q. Snurr ${ }^{\text {a,* }}$ \\ a Department of Chemical Engineering, Northwestern University, Evanston, IL 60208, USA \\ ${ }^{\mathrm{b}}$ Department of Chemistry, Northwestern University, Evanston, IL 60208, USA
}

Received 19 September 2002; received in revised form 22 May 2003; accepted 29 May 2003

\begin{abstract}
Thin-film membranes have been made from cavity-containing supramolecular building blocks known as molecular squares and evaluated for simple test separations. Permeation properties of single components and binary gas mixtures were measured through membranes made of several different molecular squares. For a small square with pyrazine edges, permeation increased in the order cyclohexane $<$ benzene $<$ toluene, consistent with the selectivities predicted from the sorption coefficients. Diffusion rates also play an important role in the permeation selectivity. For a larger square with porphyrin edges, mixture selectivities for 4-picoline over toluene were observed to be around 7-9, depending on the partial pressure. Functionalization of the interior of the porpyrin square allowed a mixture selectivity of 7 for benzene over cyclohexane. Independently measured adsorption isotherms and effective diffusion coefficients proved very helpful in understanding the effects of sorption and diffusion on the observed permeabilities.
\end{abstract}

(C) 2003 Elsevier B.V. All rights reserved.

Keywords: Diffusion; Gas and vapor permeation; Membrane preparation and structure; Microporous and porous membranes; Novel materials

\section{Introduction}

Development of novel materials for membranes continues to be one key to expanding the range of applications for membrane separation processes [1]. New materials may provide improved selectivity, higher fluxes, or tailorability for particular applications [2]. Better understanding of structure/permeability relations are also needed if materials are to be chosen, and ultimately designed, in a rational manner. A strategy for improving our structure/permeability understanding, as well as our control over membrane

\footnotetext{
* Corresponding author. Tel.: +1-847-467-2977; fax: $+1-847-467-1018$.

E-mail address: snurr@northwestern.edu (R.Q. Snurr).
}

microstructure, is to develop membranes made from well-defined building blocks or from crystalline materials. Development of zeolite membranes is one well-known example of using crystalline materials $[3,4]$. This work explores the use of cavity-containing supramolecular building blocks known as molecular squares. These units may or may not assemble into crystalline materials, but in all cases the molecular squares have cavities that retain their size and shape. The cavities may also be functionalized in a very specific manner.

Molecular squares are a class of self-assembling compounds featuring well-defined nanoscale cavities based on supramolecular coordination chemistry [5-7]. X-ray crystallography shows that in many of these materials the cavities align to form nanopores. 


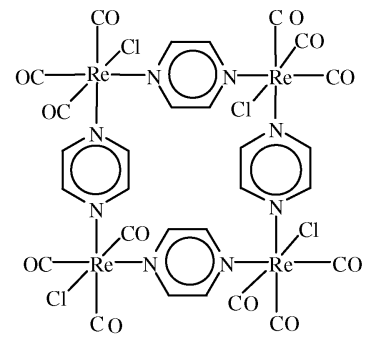

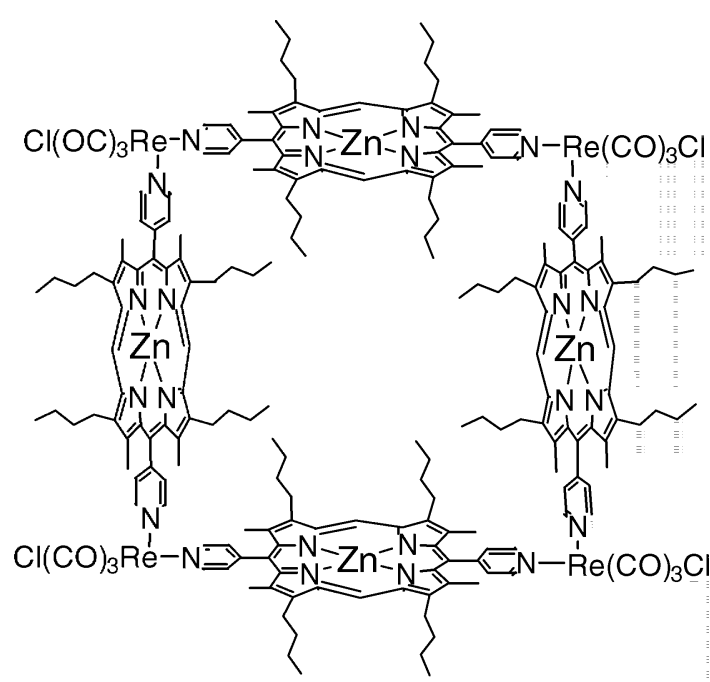

2
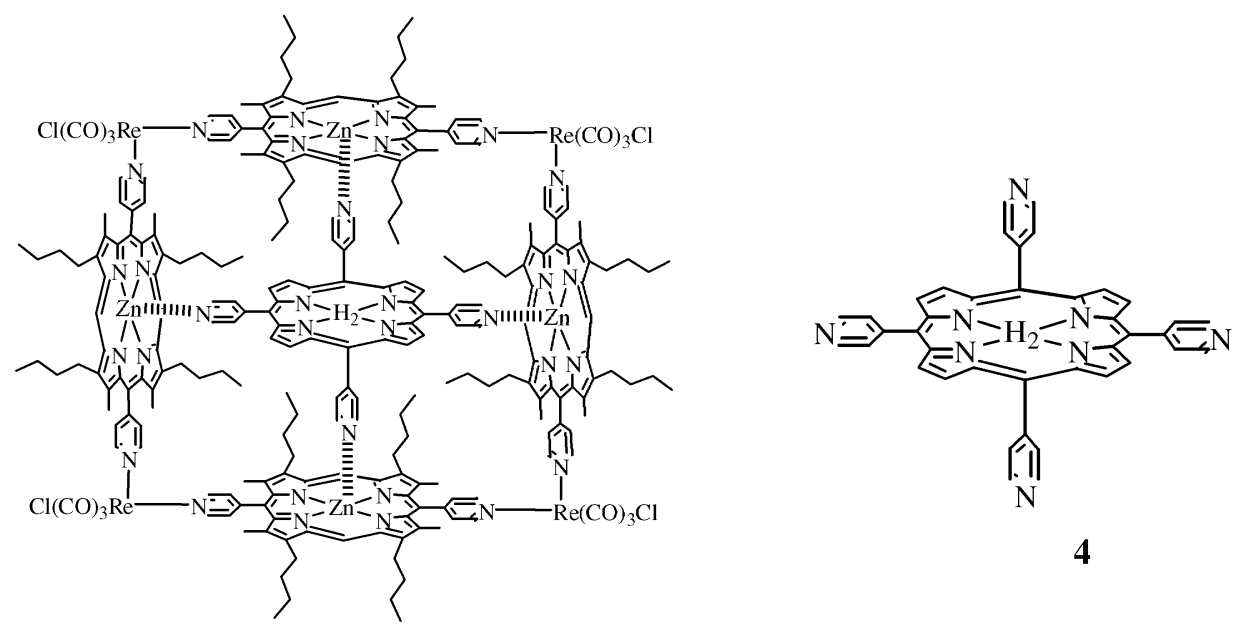

4

\section{3}

Fig. 1. Molecular squares. $\mathbf{1}$ is based on pyrazine edges, $\mathbf{2}$ is based on porphyrin edges, $\mathbf{3}$ is created by binding a tetrapyridyl porphyrin, 4, within 2.

The squares of interest to us are soluble in polar organic solvents (which allows, e.g. film casting) and insoluble in water. The three molecular squares investigated in this work are shown in Fig. 1. All feature cis-ligated $\mathrm{Re}(\mathrm{CO})_{3} \mathrm{Cl}$ corners and rigid difunctional edges. Compound $\mathbf{1}$ is based on bridging pyrazine edges, $\mathbf{2}$ has edges of $\mathrm{Zn}$ porphyrins, and $\mathbf{3}$ is based on 2 but with an additional fifth porphyrin, 4, ligated to the four walls of the square, breaking the large cavity into four smaller cavities $[8,9]$.

The crystal structure of $\mathbf{1}$ was reported by Slone et al. [8]. The squares stack in a helical spiral, but simple molecular modeling [10] shows that the interior cavities of $\mathbf{1}$ are too small for most molecules of interest. However, the modeling shows three-dimensional inter-molecular channels that weave around the 
squares. The minimum dimensions of these pores are approximately $5.6 \AA \times 5.7 \AA$, which should be accessible to small molecules such as benzene. When $\mathrm{Xe}$ is adsorbed in $\mathbf{1}$, the observed single ${ }^{129} \mathrm{Xe}$ NMR peak in the micropore region [11] indicates only one type of accessible micropore, which is consistent with the molecular modeling result that Xe can access the inter-square pores but is excluded from the intra-square cavities.

We recently fabricated thin films of $\mathbf{1}$ on porous polyester membrane supports [10] and demonstrated size-selective transport through these membranes. Simple U-tube studies with aqueous solutions showed that phenol (diameter $\sim 5.7 \AA$ ) permeated the membranes two orders of magnitude faster than $\mathrm{Fe}(1,10 \text {-phenanthroline })_{3}{ }^{2+}$ (diameter $\sim 13 \AA$; sulfate salt). The small amount of the iron complex that permeated was attributed to cracks or defects in the films. Prior electrochemical studies, using films of 1 on electrode surfaces, had also shown a size cut-off for permeation somewhere between $\sim 4$ and $7 \AA[12,13]$. Thin-film membranes of $\mathbf{2}$ allowed both phenol and iron phenanthroline to permeate but completely blocked a larger ion of $\sim 24 \AA$ [10]. This is consistent with the picture that film transport is governed by movement through the interiors of the porphyrin squares, which are roughly $18 \AA$ in diameter for 2 . While 2 allowed permeation of iron phenanthroline, thin-film membranes of the functionalized square $\mathbf{3}$ blocked its permeation, allowing only trace amounts through even after $250 \mathrm{~h}$ of exposure. However, 3 remained highly permeable to phenol; similar findings have been reported based on electrochemical measurements $[14,15]$. This is a strong indication that transport through the porphyrin square films is governed by diffusion of penetrants through the interior square cavities rather than through voids between the squares.

The previous studies of permeation through films of molecular squares have all been in aqueous phases. The goals of this work are to demonstrate that molecular square membranes can also be used in vapor-phase applications and to gain insight into the selectivities that are observed. Results for permeation of single-component and binary mixtures of several volatile organic compounds (VOCs) are presented, and independent adsorption measurements $[16,17]$ are then used to determine the role of sorption versus diffusion on permeability.

\section{Experimental}

\subsection{Materials}

The VOCs were purchased from Aldrich and used without further purification. Propane was purchased at $2.01 \%$ in helium from Matheson. Helium (high-purity grade $99.997 \%$ ) was purchased from Air Products and was purified with a moisture trap (molecular sieve 5A, 45/60 mesh, Agilent Technologies). The molecular squares 1 (various batches) and $\mathbf{2}$ (KS56a) were synthesized within the group as described in the literature [8,9]. The molecular square $\mathbf{3}$ was obtained by mixing equal volumes of a $10 \mathrm{mM}$ solution of 2 and a $10 \mathrm{mM}$ solution of tetrapyridyl porphyrin (4), both in chloroform, for at least $1 \mathrm{~h}$ [18]. Binding of $\mathbf{4}$ within the squares was verified by measuring the shift in the Soret band of thin films cast on glass slides from the resulting solution.

Thin films of squares were evaporatively cast on commercially available polyester membranes as described earlier $[10,18]$. Reproducibility of the membranes was tested in several ways. First, all permeation experiments were repeated several times with newly cast membranes each time. (The number of repetitions is indicated in Section 3 for each system.) Second, membranes were inspected using microscopy and found to be similar. Finally, films cast from $\mathbf{1}$ had reproducible thicknesses of $8 \pm 1 \mu \mathrm{m}$ as determined previously [10] from a sample of five membranes $(16 \pm 1 \mu \mathrm{m}$ for films of 2$)$. Detailed characterization of the membranes has been published previously $[10,18]$. There was one difference in the fabrication of the membranes in this work. Namely, the polyester support membranes were adhered with vacuum grease to stainless steel washers (3/4 in. OD, 11/64 in. ID, 316 SS, McMaster-Carr) rather than glass slides with holes in the center. Once the thin films of $\mathbf{1 , 2}$ or $\mathbf{3}$ were cast on the polyester support membrane/SS washer, a second washer was attached on top using Super Glue to form an airtight seal.

\subsection{Permeation experiments}

The gas phase permeation experiments were performed by placing the molecular square membranes between the two halves of a home-built permeation cell shown in Fig. 2. The cell was machined from a 


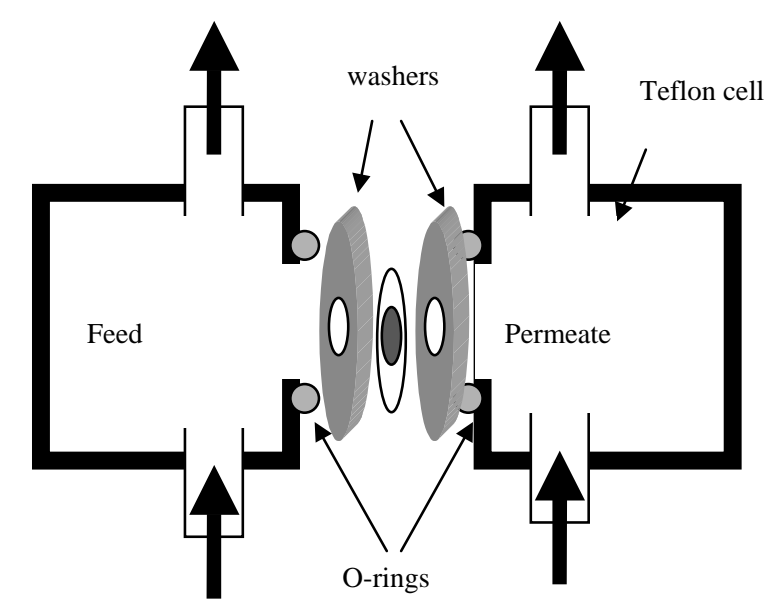

Fig. 2. Vapor-phase permeation apparatus. The molecular square membranes are sandwiched between two Teflon cells as a feed and permeate gas sweep through the cells.

$1.5 \mathrm{in.}$ OD Teflon rod. Each half was $1.7 \mathrm{in.}$ long and had an internal chamber $(0.5$ in. diameter) that contained a gas inlet and outlet, and an opening that exposed the gases to the membrane.

The two halves of the cell were sealed with Viton O-rings and were compressed by tightening four threaded rods that ran the length of the cell outside of the chambers (not shown in Fig. 2). Helium flow was controlled using mass flow controllers $(5850 \mathrm{e}$, Brooks Instrument Division). The feed contained $20 \mathrm{~cm}^{3} \mathrm{~min}^{-1}(\mathrm{ccm})$ of helium that flowed to one or two saturators making either a single component or an equimolar binary mixture of the VOCs. The permeate contained a $20 \mathrm{ccm}$ helium flow that swept past the other side of the membrane. The composition of either side was measured by directing the flow to a $1 \mathrm{ml}$ sample loop that was analyzed with a flame ionization detector in a gas chromatograph (HP 6890). An Alltech Superox column $(60 \mathrm{~m} \times 0.32 \mathrm{~mm} \times 0.3 \mu \mathrm{m})$ was used to separate cyclohexane from benzene and to separate the xylenes. An HP-5 column $(30 \mathrm{~m} \times 0.32 \mathrm{~mm} \times 0.25 \mu \mathrm{m})$ was used to perform the remaining separations. Propane was added before the feed or the permeate entered the sample loop and served as a known internal standard.

In a typical permeation experiment, the flows were set to the desired feed partial pressures, and the feed composition bypassing the cell was measured. The feed and permeate flows were then sent to the perme- ation cell, and the permeate concentration was repeatedly measured until the system achieved steady state. Once this occurred, the concentration of the feed flowing past the membrane (the retentate) was measured. The sum of the retentate and the permeate streams was typically within $95 \%$ of the feed composition, thus good mass balance was achieved. A different membrane was used for each permeation experiment.

\section{Results and discussion}

\subsection{Pyrazine square membranes}

The transport of single-component and binary mixtures of cyclohexane, benzene and toluene was measured across pyrazine square (1) membranes. For these permeation experiments, the feed partial pressure of each VOC was $\sim 20 \mathrm{~mm} \mathrm{Hg}$. From the permeate and retentate concentrations, the fluxes $\left(J_{i}\right)$ of the VOCs and the partial pressure drops $\left(\Delta p_{i}\right)$ across the membrane were calculated. Using these values, the permeabilities of the VOCs were calculated using Eq. (1)

$J_{i}=\frac{D_{i} K_{i} \Delta p_{i}}{\ell}=\frac{P_{i} \Delta p_{i}}{\ell}$

where $\ell$ is the film thickness $(\ell=8 \mu \mathrm{m}$ for $\mathbf{1}[10]), D_{i}$ the diffusion coefficient and $K_{i}$ the sorption coefficient [19]. The permeability is defined as the product of the diffusion and the sorption coefficients, $P_{i}=D_{i} \times K_{i}$. The permeation selectivity in a binary mixture is then defined as the ratio of the permeabilities, $\alpha_{i j}=P_{i} / P_{j}$. Blank polyester support membranes provided minimal resistance to the transport of the VOCs.

The permeabilities for the single-component transport of cyclohexane, benzene and toluene across the pyrazine square (1) membranes are shown on the left side of Fig. 3. The areas in the figure represent the range over which the permeabilities span for a given VOC. The values for benzene and toluene are based on two permeation experiments each, while the permeability of cyclohexane is based on three measurements. The values show that benzene and cyclohexane permeate the pyrazine square membranes with very similar permeabilities $\left(\mathcal{O}\left(10^{-8}\right)\right)$, while the transport of toluene occurs with a permeability over an order of magnitude larger, centering at $\sim 5 \times 10^{-7} \mathrm{~cm} \mathrm{~cm}^{3}$ (STP) $\mathrm{cm}^{-2} \mathrm{~s}^{-1} \mathrm{~cm} \mathrm{Hg}^{-1}$. 


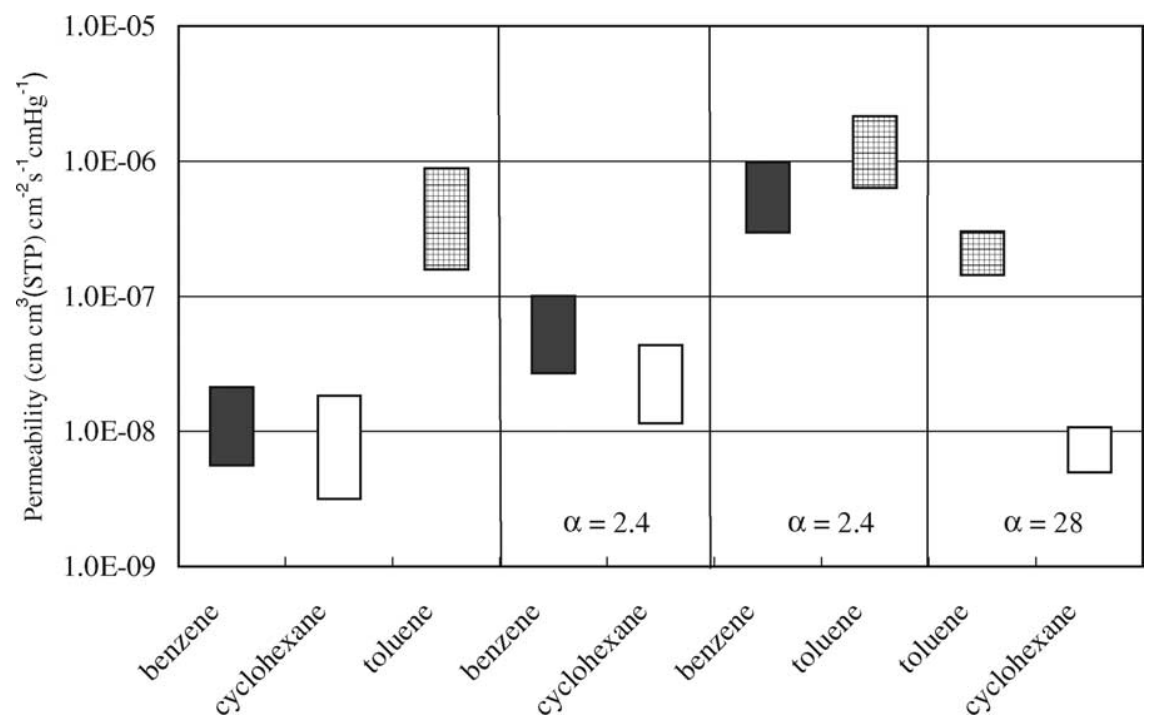

Fig. 3. Single component (left) and binary mixture (right) gas phase permeabilities for pyrazine square (1) membranes.

$\left(1\right.$ Barrer $=10^{-10} \mathrm{~cm} \mathrm{~cm}^{3}(\mathrm{STP}) \mathrm{cm}^{-2} \mathrm{~s}^{-1} \mathrm{~cm} \mathrm{Hg}^{-1} \approx$ $75 \mathrm{~cm}^{2} \mathrm{~s}^{-1}$ [20].)

The single-component sorption coefficients, shown in Table 1, lend some insight into the values of these permeabilities since the permeabilities are a product of the sorption coefficient and the diffusion coefficient. These sorption coefficients for $\mathbf{1}$ were measured using quartz crystal microgravimetry by Keefe et al. [16]. At low partial pressures, a linear relation exists between the partial pressure and the amount of VOC adsorbed in microporous materials. Thus, Henry constants are the sorption coefficients used to define the permeability. The Henry constant for benzene was measured over a range of pressures from 5.6 to $26 \mathrm{~mm} \mathrm{Hg}$, which encompasses the feed partial pressure of $20 \mathrm{~mm} \mathrm{Hg}$ for benzene in these permeation experiments, validating its use here [16]. Binding constants for cyclohexane and toluene were measured over similar ranges. The binding constants predict relative permeabilities for cyclohexane, benzene, and toluene of 1:2.7:5.7 if

Table 1

Henry constants for thin films of 1 [16]

\begin{tabular}{lccc}
\hline & Cyclohexane & Benzene & Toluene \\
\hline$K\left(\mathrm{M}^{-1}\right)$ & $58 \pm 9$ & $157 \pm 8$ & $332 \pm 26$ \\
$K_{i} / K_{\text {cyclohexane }}$ & 1 & 2.7 & 5.7 \\
\hline
\end{tabular}

the diffusion coefficients are equal. However, the observed permeability ratios are 1:1:50, suggesting that diffusion effects also play an important role in the permeation.

The transport properties of binary mixtures of cyclohexane, benzene, and toluene across the pyrazine square (1) membranes were also measured, and the resulting permeabilities are shown on the right side of Fig. 3. For the cyclohexane/benzene mixtures the permeabilities of both molecules increased somewhat over the single-component values. Benzene permeates the membrane slightly faster than cyclohexane in the mixture, leading to a permeation selectivity towards the transport of benzene, $\alpha_{\text {benzene/cyclohexane }}=2.4$. This is consistent with the single-component sorption selectivity of 2.7. However, it is unclear why this selectivity is only observed in the mixture and not in the single-component permeation studies. One possibility is that in the single-component systems, the diffusivities and the sorption coefficients of the two species are different, but they compensate to make the single-component permeabilities equal. In the mixtures, the diffusivities are more likely to be equal if we draw from limited experience with zeolites. In several zeolite systems where single-component and binary diffusivities have been measured, the diffusivities tend to become similar in the mixtures $[21,22]$. If this also 
holds here, then it would explain why the mixture selectivity correlates with the sorption coefficients while the single-component permeabilities do not.

For benzene/toluene mixtures a slight increase in the toluene permeability over the single-component value was observed (within the error bar), while there was a significant increase in the permeability of benzene. The permeation selectivity towards the transport of toluene was calculated to be $\alpha_{\text {toluene/benzene }}=2.4$. This selectivity is again consistent with the selectivity predicted by the single-component sorption data, which gives a selectivity of $K_{\text {toluene }} / K_{\text {benzene }}=2.1$. However, this does not explain the increase in the benzene permeability of over an order of magnitude when compared to the single-component case. The single-component permeation data predicts a toluene selectivity of $\sim 50$. It is possible that diffusional effects are causing this increase [23], although the nature of these effects is uncertain.

The largest selectivity was observed when the transport of a binary mixture of toluene and cyclohexane was measured across the pyrazine square (1) membranes. The permeabilities were based on two measurements and are fairly consistent with the values measured for the single-component systems, with both being slightly lower as shown in Fig. 3. For the mixture, the permeation selectivity was calculated to be $\alpha_{\text {toluene/cyclohexane }}=28$. The ratio of Henry constants indicate that the toluene preferentially adsorbs, but this only accounts for a factor of 5.7. The remaining preference for the transport of toluene over cyclohexane most likely arises from diffusion effects. However, the nature of these effects again warrants further investigation. It is unclear why the toluene selectivity for this mixture is consistent with the single-component permeation data, while the selectivities for the other two mixtures are consistent to those predicted from the single-component sorption data.

For all three mixtures, the permeation selectivity is qualitatively consistent with the selectivity predicted from the Henry constants. The molecule with the larger binding constant preferentially permeated the membranes. However, quantitative agreement was not observed, suggesting that other effects, such as diffusion, play an important role and help account for the increase in the benzene permeability in the mixtures and the large selectivity towards the transport of toluene over cyclohexane.

\subsection{Zinc porphyrin square}

The transport of three binary mixtures was measured across the zinc porphyrin square (2) membranes. The partial pressures of the VOCs in the feed were lower than those used for the pyrazine square (1) membranes due to the lower vapor pressures of these permeants. The first system was a binary mixture of 4-picoline (4-methyl pyridine) and toluene, measured at two different feed concentrations. The partial pressure of both molecules in the feed was $\sim 4.0 \mathrm{~mm} \mathrm{Hg}$ for four different membranes and $\sim 1.7 \mathrm{~mm} \mathrm{Hg}$ for two different membranes. At both feed concentrations, 4-picoline had a larger permeability than toluene as shown in Table 2. As the partial pressure of the VOCs decreased from 4.0 to 1.7 , the selectivity towards the transport of 4-picoline increased from 7.3 to 9.4. Single-component adsorption data summarized in Table 3 can be used to explain this selectivity. Adsorption isotherms measured using a novel diffraction method [17] show that there is a selectivity of $\sim 5$ towards the adsorption of 4-picoline over toluene in thin films of $\mathbf{2}$ in this pressure range. This preference is due in part to the ability of the nitrogen atoms of 4-picoline to bind to the zinc atoms of 2 , while the toluene lacks nitrogen atoms. An important additional role, however, is played by van der Waals interactions.

The zinc porphyrin square (2) membranes were also exposed to a binary mixture of 2-picoline (2-methyl pyridine) and 4-picoline, each having a feed partial pressure of $\sim 3.4 \mathrm{~mm} \mathrm{Hg}$. The permeabilities are also listed in Table 2. These isomers were chosen because

Table 2

Permeabilities and selectivities of various VOC binary mixtures through zinc porphyrin square (2) membranes

\begin{tabular}{|c|c|c|c|}
\hline & $\begin{array}{l}\text { Partial } \\
\text { pressure } \\
(\mathrm{mm} \mathrm{Hg})\end{array}$ & $\begin{array}{l}\text { Permeability } \\
\left(\mathrm{cm} \mathrm{cm}^{3}(\mathrm{STP})\right. \\
\left.\mathrm{cm}^{-2} \mathrm{~s}^{-1} \mathrm{~cm} \mathrm{Hg}\right)\end{array}$ & $\begin{array}{l}\text { Selectivity, } \\
\alpha_{i j}\end{array}$ \\
\hline 4-Picoline & 4.0 & $5.1 \pm 0.8 \times 10^{-6}$ & \multirow{2}{*}{$7.3 \pm 1.6$} \\
\hline Toluene & 4.0 & $7.0 \pm 2.7 \times 10^{-7}$ & \\
\hline 4-Picoline & 1.7 & $1.6 \pm 0.9 \times 10^{-6}$ & \multirow[t]{2}{*}{$9.4 \pm 0.2$} \\
\hline Toluene & 1.7 & $1.7 \pm 0.9 \times 10^{-7}$ & \\
\hline 4-Picoline & 3.4 & $5.3 \pm 0.7 \times 10^{-6}$ & \multirow{2}{*}{$1.7 \pm 0.1$} \\
\hline 2-Picoline & 3.4 & $3.0 \pm 0.4 \times 10^{-6}$ & \\
\hline Toluene & 3.7 & $9.0 \pm 0.6 \times 10^{-6}$ & \multirow[t]{2}{*}{$1.1 \pm 0.1$} \\
\hline $\begin{array}{l}\text { Methyl } \\
\text { cyclohexane }\end{array}$ & 3.7 & $8.1 \pm 0.5 \times 10^{-6}$ & \\
\hline
\end{tabular}


Table 3

Selected single-component adsorption and diffusion data for VOCs in thin films of porphyrin molecular square (2) from Li and Hupp $[17]^{\mathrm{a}}$

\begin{tabular}{llll}
\hline & $\begin{array}{l}\text { Pressure } \\
(\mathrm{mm} \mathrm{Hg})\end{array}$ & $\begin{array}{l}\text { Loading } \\
(\mathrm{molec} / \mathrm{square})\end{array}$ & $\begin{array}{l}\text { Diffusivity } \\
\left(\mathrm{cm}^{2} / \mathrm{s}\right)\end{array}$ \\
\hline 4-Picoline & 4.0 & 60.4 & $1.1 \times 10^{-11}$ \\
$\begin{array}{l}\text { Toluene } \\
\text { Ratio }\end{array}$ & 4.3 & 12.3 & $4.9 \times 10^{-12}$ \\
4-Picoline & 1.7 & 3.9 & 2.2 \\
Toluene & 1.1 & 6.5 & $1.4 \times 10^{-12}$ \\
Ratio & & 4.8 & $2.2 \times 10^{-12}$ \\
4-Picoline & 3.5 & 49.2 & 0.64 \\
2-Picoline & 3.4 & 31.6 & $3.4 \times 10^{-12}$ \\
Ratio & & 1.6 & $2.1 \times 10^{-12}$ \\
$\begin{array}{l}\text { Toluene } \\
\text { Methyl } \\
\quad \text { cyclohexane }\end{array}$ & 4.3 & 12.3 & 1.6 \\
Ratio & 4.2 & 6.4 & $4.9 \times 10^{-12}$ \\
\hline
\end{tabular}

${ }^{a}$ Data points were chosen to correspond as closely as possible to the pressures in Table 2.

placement of a sterically demanding methyl group in the ortho position (2-picoline) is known to inhibit adsorption to the zinc atoms of $\mathbf{2}$, compared to having the methyl group in the para position (4-picoline) [24]. We reasoned that a large permeation selectivity in favor of the para isomer might be observed. Both molecules permeated the zinc porphyrin square membranes, with a permeation selectivity of $\alpha_{4 \text {-picoline } / 2 \text {-picoline }}=1.7$. At the partial pressure used, the independent adsorption experiments (Table 3) yielded an overall adsorption selectivity of 1.6, indicating that the position of the methyl group plays little role in adsorption. At much lower partial pressures, however, there is a very strong adsorption preference (close to two orders of magnitude) for 4-picoline over 2-picoline. The preference is clearly based on 4-picoline ligation of the few available $\mathrm{Zn}$ (II) sites. That the preferential adsorption does not translate into a similarly large permeation selectivity could be due to lack of significant participation of the few strongly adsorbed 4-picoline molecules in the transport process. It is interesting to note that 4-picoline has the same permeability in both the 4-picoline/toluene and 4-picoline/2-picoline mixtures.

The transport of a binary mixture of toluene and methyl cyclohexane across the zinc porphyrin square
(2) membranes was also measured in order to test a pair where neither molecule had a nitrogen atom that could bind to the zinc atoms of the porphyrins. The feed contained a partial pressure of $3.7 \mathrm{~mm} \mathrm{Hg}$ of each VOC. The permeabilities for this mixture are given in Table 2 and show that neither component permeates the membranes preferentially. The single-component isotherm data in Table 3 gives an adsorption selectivity for toluene over methyl cyclohexane of 1.9 , which is only slightly higher than the selectivity from the binary permeability studies (1.1).

In addition to the single-component isotherms, the effective diffusion coefficients of various molecules in films of 2 were also measured [17]. Some of these results are also reported in Table 3. Compared to the ratios of adsorbed loadings, the ratios of diffusivities do not differ as much from unity, ranging from about 0.5 to 2.2. For these porphyrin square systems, which have larger pores than the pyrazine squares, it is not surprising that the diffusivities of various small molecules are fairly similar. As just shown, the permeability selectivities can be largely explained by differences in adsorption for films of $\mathbf{2}$. However, one cannot say that diffusion rates play no role. For example, it is interesting to note that despite the inability of toluene and methyl cyclohexane to bind to the zinc atoms of the square, the permeabilities for this mixture are larger than those for the other mixtures in the zinc porphyrin square membranes. The diffusivity data in Table 3 support the intuitive concept that, at low loadings, species that bind more strongly tend to have lower diffusivities. However, because the diffusion coefficients tend to increase with increasing loading, it can sometimes be difficult to predict this kind of behavior without experimental data such as those in Table 3.

\subsection{Functionalized zinc porphyrin square membranes}

The zinc porphyrin squares (2) were functionalized with tetrapyridyl porphyrin (4), reducing the internal cavity of the squares from a large single cavity measuring $\sim 18 \AA \times 18 \AA$ to four smaller cavities less than $6 \AA$ in diameter. The transport of two binary mixtures was measured across membranes made from the functionalized squares $\mathbf{3}$, and the permeabilities are shown in Table 4. In the toluene/benzene mixture, the toluene permeability was slightly larger 
Table 4

Permeabilities and selectivities of two binary mixtures for functionalized zinc porphyrin square (3) membranes

\begin{tabular}{llll}
\hline & $\begin{array}{l}\text { Partial } \\
\text { pressure } \\
(\mathrm{mm} \mathrm{Hg})\end{array}$ & $\begin{array}{l}\text { Permeability } \\
\left(\mathrm{cm} \mathrm{cm}^{3}(\mathrm{STP})\right.\end{array}$ & $\begin{array}{l}\text { Selectivity, } \\
\left.\mathrm{cm}_{i j} \mathrm{~s}^{-1} \mathrm{~cm} \mathrm{Hg}\right)\end{array}$ \\
\hline Toluene & 19 & $2.0 \pm 0.8 \times 10^{-7}$ & 2.1 \\
Benzene & 22 & $1.0 \pm 0.3 \times 10^{-7}$ & \\
Benzene & 22 & $7 \pm 5 \times 10^{-9}$ & 7.0 \\
Cyclohexane & 22 & $9 \pm 5 \times 10^{-10}$ & \\
\hline
\end{tabular}

than that of benzene, giving a permeation selectivity of $\alpha_{\text {toluene/benzene }}=2.1$. In the benzene-cyclohexane mixture, the benzene permeability was much larger than the cyclohexane permeability, yielding a selectivity of $\alpha_{\text {benzene/cyclohexane }}=7.0$. Single-component adsorption data are summarized in Table 5 [17]. Adsorption effects alone would predict smaller selectivities of around 1.5 for both systems. Diffusion likely plays an important role in these small pores.

Separation of xylene isomers is quite important industrially. Therefore, the transport of two additional binary mixtures, $o$-xylene $/ p$-xylene and $m$-xylene/ $p$-xylene, was measured across the functionalized zinc porphyrin square membranes. The feed partial pressures were 3.0 and $3.5 \mathrm{~mm} \mathrm{Hg}$, respectively, for the two mixtures. No selectivity towards either isomer was observed for either of the two mixtures. The permeabilities for the $o-/ p$-xylene mixture were both $\sim 6 \times 10^{-8}$ while the permeabilities of the $m-/ p$-xylene mixture were both $\sim 2 \times 10^{-7} \mathrm{~cm} \mathrm{~cm}^{3}$ (STP) $\mathrm{cm}^{-2} \mathrm{~s}^{-1} \mathrm{~cm} \mathrm{Hg}$. Discrimination of these very similar molecules was not possible with the current generation of membranes.

Table 5

Selected single-component adsorption data for VOCs in thin films of functionalized porphyrin molecular squares (3) from $\mathrm{Li}$ and Hupp [17]

\begin{tabular}{lll}
\hline & Pressure $(\mathrm{mm} \mathrm{Hg})$ & Loading (molec/square) \\
\hline Toluene & $15.6^{\mathrm{b}}$ & 9.4 \\
Benzene & 18.4 & 6.6 \\
Cyclohexane & 18.9 & 4.1
\end{tabular}

\footnotetext{
${ }^{a}$ Data points were chosen to correspond as closely as possible to the pressures in Table 4.

${ }^{\mathrm{b}}$ Highest pressure measured for toluene.
}

\section{Conclusions}

Permeation properties of single components and binary gas mixtures were measured through thin-film membranes made of several molecular squares. For a small square with pyrazine edges, permeation increased in the order cyclohexane $<$ benzene $<$ toluene, consistent with the selectivities predicted from the pure-component sorption coefficients. However, quantitative agreement was not observed, suggesting that other effects, such as diffusion, play an important role in the permeation selectivity. In some cases, quite favorable selectivities were observed, e.g. a selectivity of 28 for toluene in binary cyclohexane/toluene mixtures. For a larger square with porphyrin edges, mixture selectivities for 4-picoline over toluene were observed to be around 7-9, depending on the partial pressure. However, discrimination of 2-picoline versus 4-picoline was not possible under the conditions used here. Functionalization of the interior of the porpyrin square allowed a mixture selectivity of 7 for benzene over cyclohexane, but the system was not able to separate the isomers of xylene. Some of the selectivities observed in these systems approach or exceed general industrial targets $(\sim 10)$ for membrane separations [25]. Independently measured adsorption isotherms and effective diffusion coefficients proved very helpful in understanding the effects of sorption and diffusion on the observed permeabilities.

\section{Acknowledgements}

We gratefully acknowledge Katherine Splan for synthesizing the zinc porphyrin square and Prof. SonBinh Nguyen for helpful discussions. We thank the US Department of Energy for financial support.

\section{References}

[1] W.J. Koros, Membranes: learning a lesson from nature, Chem. Eng. Prog. (October 1995) 68-81.

[2] T.J. Barton, L.M. Bull, W.G. Klemperer, D.A. Loy, B. McEnaney, M. Misono, P.A. Monson, G. Pez, G.W. Scherer, J.C. Vartuli, O.M. Yaghi, Tailored porous materials, Chem. Mater. 11 (1999) 2633-2656.

[3] M. Tsapatsis, G.R. Gavalas, Synthesis of porous inorganic membranes, MRS Bull. (March 1999) 30-35.

[4] M.E. Davis, Ordered porous materials for emerging applications, Nature 417 (2002) 813-821. 
[5] M. Fujita, Metal-directed self-assembly of two- and threedimensional synthetic receptors, Chem. Soc. Rev. 27 (1998) 417-425.

[6] P.J. Stang, B. Olenyuk, Self-assembly, symmetry, and molecular architecture: coordination as the motif in the rational design of supramolecular metallacyclic polygons and polyhedra, Acc. Chem. Res. 30 (1997) 502-518.

[7] P.H. Dinolfo, J.T. Hupp, Supramolecular coordination chemistry and functional microporous molecular materials, Chem. Mater. 13 (2001) 3113-3125.

[8] R.V. Slone, J.T. Hupp, C.L. Stern, T.E. Albrecht-Schmitt, Self-assembly of luminescent molecular squares featuring octahedral rhenium corners, Inorg. Chem. 35 (1996) 40964097.

[9] R.V. Slone, J.T. Hupp, Synthesis, characterization, and preliminary host-guest binding studies of porphyrinic molecular squares featuring fac-tricarbonyrhenium (I) chloro corners, Inorg. Chem. 36 (1997) 5422-5423.

[10] K.F. Czaplewski, J.T. Hupp, R.Q. Snurr, Molecular squares as molecular sieves: size-selective transport through porous-membrane-supported thin-film materials, Adv. Mater. 13 (2001) 1895-1897.

[11] Y.J. Kim, S. Chempath, P.H. Dinolfo, J.T. Hupp, R.Q. Snurr, Unpublished.

[12] S. Belanger, B.C. Anderson, J.T. Hupp, Preliminary electrochemical studies of the permeation of mesoporous films of the "molecular square" compound, $\left[\operatorname{Re}\left(\mathrm{CO}_{3}\right)(\mathrm{Cl})(\mu\right.$ pyrazine)]4, by redox-silent cations: redox-active counter anions as reporters on the cation size dependence of the permeation process, in: Electrochemical Society Proceedings on Molecular Functions of Electroactive Thin Films, vol. 98, 1998, pp. 208-214.

[13] S. Belanger, J.T. Hupp, C.L. Stern, R.V. Slone, D.F. Watson, T.M. Carrell, Thin-film molecular materials based on tetrametallic "squares": nanoscale porosity and size selective guest transport characteristics, J. Am. Chem. Soc. 121 (1999) 557-563.

[14] S. Belanger, J.T. Hupp, Porphyrin-based thin-film molecular materials featuring highly adjustable nanoscale porosity and permeability characteristics, Angew. Chem. 38 (1999) 22222224.

[15] M.E. Williams, J.T. Hupp, Scanning electrochemical microscopy assessment of rates of molecular transport through thin films of mesoporous films of porphyrinic "molecular squares", J. Phys. Chem. B 105 (2001) 8944-8950.

[16] M.H. Keefe, R.V. Slone, J.T. Hupp, K.F. Czaplewski, R.Q. Snurr, C.L. Stern, Mesoporous thin films of "molecular squares" as sensors for volatile organic compounds, Langmuir 16 (2000) 3964-3970.

[17] J. Li, J.T. Hupp, Unpublished.

[18] K.F. Czaplewski, Molecular squares and zeolites as novel membranes and hydrocarbon adsorbents, Ph.D. Thesis, Northwestern University, Evanston, 2001.

[19] M. Mulder, Basic Principles of Membrane Technology, Kluwer Academic Publishers, Boston, 1996.

[20] W.J. Koros, A.S. Michaels, Three score years with membranes: The legacy of R.M. Barrer, in: M.M.J. Treacy, B.K. Marcus, M.E. Bisher, J.B. Higgins (Eds.), Proceedings of the 12th International Zeolite Conference, Materials Research Society, Warrendale, PA, 1999, pp. 25-32.

[21] S.S. Nivarthi, A.V. McCormick, Diffusion of coadsorbed molecules in zeolites: a pulsed field gradient NMR study, J. Phys. Chem. 99 (1995) 4661-4666.

[22] R.Q. Snurr, J. Kärger, Molecular simulations and NMR measurements of binary diffusion in zeolites, J. Phys. Chem. B 101 (1997) 6469-6473.

[23] H.D. Kamaruddin, W.J. Koros, Some observations about the application of Fick's first law for membrane separation of multicomponent mixtures, J. Membr. Sci. 135 (1997) 147159.

[24] S. Belanger, M.H. Keefe, J. Welch, J.T. Hupp, Rapid derivatization of mesoporous thin-film materials based on $\operatorname{Re}(\mathrm{I})$ zinc-porphyrin "molecular squares": selective modification of mesopore size and shape by binding of aromatic nitrogen donor ligands, Coord. Chem. Rev. 192 (1999) 29-45.

[25] J.L. Humphrey, G.E.I. Keller, Separation Process Technology, McGraw-Hill, New York, 1997. 